\title{
APLIKASI PUSTAKABASA \\ SEBAGAI MEDIA PENCEGAHAN KEPUNAHAN \\ BAHASA DAERAH DI NUSANTARA
}

\author{
Kresna Galuh D. Herlangga ${ }^{1}$, Andi Susilo ${ }^{2}$ \\ Fakultas Teknologi Informasi, Universitas Respati Indonesia \\ Jl. Bambu Apus I No. 3 Cipayung Jakarta Timur \\ E-mail : ${ }^{1}$ kresnagaluh@gmail.com, ${ }^{2}$ as@fti.urindo.ac.id
}

\begin{abstract}
ABSTRAKS
Dalam Ethnologue: Language of The World (2009), tercatat bahwa Indonesia memiliki 726 jenis bahasa daerah dan merupakan negara terbanyak kedua dalam jumlah bahasa daerahnya setelah Papua New Guinea yang memiliki 842 bahasa daerah. Dalam perjalanannya, tidak semua bahasa daerah mampu bertahan dan lestari, ada sekitar 257 bahasa daerah di Indonesia yang sedang terancam punah, dan 10 bahasa daerah telah punah. Oleh karena itu diperlukan upaya pencegahan agar laju kepunahan bahasa daerah tersebut dapat diperlambat atau bahkan dihentikan. Salah satu upaya yang dapat dilakukan adalah dengan pendokumentasian. PustakaBasa (http://www.pustakabasa.com) merupakan sebuah aplikasi kamus berbasis web yang dibangun untuk mendokumentasikan kosakata-kosakata dari seluruh bahasa daerah di Nusantara. Metodologi SDLC dengan pendekatan berorientasi obyek UML versi 2 digunakan untuk membangun aplikasi ini. Dengan konsep open content memungkinkan penggarapan kebahasaan bisa dilakukan secara gotong-royong oleh seluruh masyarakat bahasa di Indonesia. Dengan demikian proses pendokumentasian bisa lebih optimal, dan diharapkan dapat mengatasi masalah kepunahan bahasa daerah di Indonesia.
\end{abstract}

Kata kunci: PustakaBasa, bahasa daerah, open content, UML versi 2.

\section{LATAR BELAKANG}

Dalam Ethnologue: Language of The World (2009), tercatat bahwa Indonesia memiliki 726 jenis bahasa daerah yang tersebar dari Sabang sampai Merauke. Dengan 726 bahasa daerah, Indonesia merupakan negara yang memiliki bahasa daerah terbanyak ke-2 di dunia setelah Papua New Guinea yang memiliki 842 bahasa daerah [1]. Koleksi ini merupakan sebuah prestasi yang membanggakan dan patut untuk kita jaga dan lestarikan. Namun sayang, seiring waktu berlalu tidak semua bahasa daerah yang ada di Indonesia mampu bertahan dan bisa lestari. Ada beberapa bahasa daerah yang saat ini berpotensi untuk mengalami kepunahan, bahkan ada beberapa bahasa daerah yang telah benar-benar punah, karena tidak ada lagi penuturnya.

Dalam kaitannya dengan kepunahan bahasa daerah, Wurm (1998) sebagaimana dikutip dari Crystal (2000) mengklasifikasikan kondisi "kesehatan" bahasa dapat diklasifikasikan ke dalam beberapa tahap [2]:

a. Potentially endangered languages, yaitu bahasa yang dianggap berpotensi terancam punah adalah bahasa yang secara sosial dan ekonomi tergolong minoritas serta mendapat tekanan yang cukup besar dari bahasa mayoritas. Generasi mudanya sudah mulai berpindah ke bahasa mayoritas.

b. Endangered languages, yaitu bahasabahasa yang terancam punah adalah bahasa yang tidak lagi mempunyai generasi muda yang dapat berbahasa daerah. Penutur yang fasih hanyalah kelompok generasi menengah (dewasa).

c. Seriously endangered languages, yaitu bahasa-bahasa yang dianggap sangat terancam punah adalah bahasa yang berpenutur generasi tua berusia di atas 50 tahun.

d. Moribund languages, yaitu bahasa-bahasa yang dianggap sekarat adalah bahasa yang dituturkan oleh beberapa orang sepuh yaitu sekitar 70 tahun ke atas.

e. Extinct languages, yaitu bahasa-bahasa yang dianggap punah adalah bahasa yang penuturnya tinggal satu orang.

Dalam kasus bahasa daerah di Indonesia, bahasa yang berada di ambang kepunahan misalnya adalah bahasa Hamap di Kabupaten Alor (Provinsi Nusa Tenggara Timur). Penuturnya saat ini 
diperkirakan hanya tinggal sekitar 1000 orang. Berdasarkan klasifikasi yang dikemukakan oleh Wurm (1998), bahasa Hamap masuk ke dalam kategori pertama, yakni sebagai bahasa yang berpotensi terancam punah (potentially endangered languages). Hal ini dikarenakan generasi mudanya lebih cenderung menggunakan bahasa Melayu Alor daripada bahasa etnik mereka sendiri yaitu bahasa Hamap [3].

Selain bahasa yang berpotensi terancam punah, berdasarkan penelitian dari cf. Pieter J dan Helja Heikkinen Clouse tahun 1991 ada sekitar 257 bahasa daerah di Indonesia yang terancam punah (endangered languages) [4]. Adapun detailnya digambarkan pada Tabel 1.

Tabel 1 Bahasa daerah yang terancam punah dan persebarananya di Indonesia

\begin{tabular}{|l|c|}
\hline Nama Pulau & $\begin{array}{c}\text { Total Bahasa } \\
\text { Daerah }\end{array}$ \\
\hline Papua & 208 \\
\hline Maluku & 4 \\
\hline Maluku Utara & 3 \\
\hline Sulawesi & 16 \\
\hline NTT & 12 \\
\hline Kalimantan & 13 \\
\hline Sumatra & 1 \\
\hline JUMLAH & 257 \\
\hline
\end{tabular}

Sedangkan bahasa-bahasa yang telah dinyatakan punah (extinct languages) menurut hasil penelitian mantan Kepala Balai Bahasa Jayapura Frans Rumbrawer tahun 1999, sembilan bahasa di Papua sudah punah, yakni bahasa Bapu, Darbe, dan Wares dari Kabupaten Sarmi, bahasa Taworta dan Waritai dari Jayapura, bahasa Murkim dan Walak dari Jayawijaya, bahasa Meoswar dari Manokwari, dan bahasa Loegenyem dari Raja Ampat. Selain itu ada juga sebuah bahasa dari Maluku Utara yang telah punah, yakni bahasa Ibu.

Ada banyak faktor yang menyebabkan sebuah bahasa daerah di Indonesia bisa terancam punah atau bahkan mengalami kepunahan. Menurut Fanny Henry Tondo (2009) dalam jurnal ilmiah yang berjudul "Kepunahan Bahasa-bahasa daerah: Faktor Penyebab dan Implikasi Etnolinguistis”, bahwa faktor-faktor penyebab sebuah bahasa bahasa daerah di Indonesia terancam punah atau mengalami kepunahan adalah sebagai berikut [5]:

a. Pengaruh bahasa mayoritas di lokasi bahasa daerah tersebut digunakan.

b. Kondisi masyarakat penuturnya yang bilingual atau bahkan multilingual. c. Faktor globalisasi.

d. Faktor migrasi (migration).

e. Perkawinan antaretnik (intermarriage).

f. Bencana alam dan musibah.

g. Kurangnya pengajaran terhadap bahasa etnik sendiri.

h. Kurangnya intensitas berbahasa daerah khususnya dalam ranah keluarga.

i. Faktor ekonomi.

j. Persaingan dengan bahasa Indonesia.

Sungguh sangat disayangkan bila sebuah bahasa daerah yang ada di Indonesia satu persatu mengalami kepunahan. Itu berarti kita kehilangan sebuah kekayaan budaya yang sangat bernilai. Agar bahasa daerah bisa terhindar dari kepunahan dan bisa tetap lestari diperlukan upaya-upaya penyelamatan, seperti mengajarkannya kepada anak-anak di usia dini, menerapkannya minimal di lingkungan keluarga, memasukannya pada kurikulum sekolah, dan yang tidak kalah penting adalah pendokumentasian.

Dengan adanya teknologi yang semakin berkembang, proses pendokumentasian bahasa pun dilakukan tidak hanya dalam berbentuk kamus cetak, namun telah banyak inovasi-inovasi lainnya, misalnya kamus online yang dibuat oleh Harrison bersama National Geographic sebagaimana dikutip dalam Kompas.com (Minggu, 19 Februari 2012). Kamus itu berisi 32.000 kata dalam 8 bahasa yang terancam punah. Selain itu juga proses pendokumentasian bahasa telah diterapkan juga untuk aplikasi berbasis mobile, seperti aplikasi pembelajaran bahasa Tuvan yang ada pada iPhone.

Perkembangan teknologi memang telah banyak membantu dalam proses pendokumentasian bahasa untuk menghindari kepunahan. Dalam kasusnya di Indonesia, juga telah berkembang banyak inovasiinovasi teknologi yang berkaitan dengan pendokumentasian bahasa daerah, baik yang berupa kamus online seperti kamusjowo.com, kamusbahasasunda.com dan bahasa-nusantara.com, selain itu juga ada yang berupa translator seperti translatornusantara.com. Tidak hanya di lingkungan web saja, di lingkungan desktop pun telah ada seperti software 5 Kamus Bahasa Daerah (Ngapak, Ambon, Jawa, Nias dan Sunda). Namun pendokumentasian tersebut dirasa belum memadai untuk mendokumentasikan seluruh bahasa daerah yang ada di Indonesia. Oleh karena itu dibutuhkan sebuah media baru yang bisa berfungsi sebagai 
media pendokumentasian yang mencakup seluruh bahasa daerah di Nusantara dengan konsep yang tepat. Atas dasar tersebut, maka akan dibangun sebuah aplikasi kamus online berbasis web dengan menerapkan konsep open content dengan nama PustakaBasa.

\section{METODOLOGI}

Metodologi SDLC (Systems Development Life Cycle) dalam pengembangan aplikasi PustakaBasa ini menggunakan pendekatan berorientasi obyek dengan pemodelan UML versi 2 [6] terdiri dari 4 bagian, yaitu:

1) Pengumpulan Data

Pengumpulan data dilakukan dengan menggunakan beberapa tahapan, yaitu (1) pencarian data kepunahan bahasa daerah, (2) studi bahasa daerah, dan (3) pengumpulan kosakata bahasa daerah.

2) Analisis

Analisis dilakukan setelah proses pengumpulan data, meliputi (1) survei aplikasi sejenis yang telah ada dan berkembang, (2) analisis aplikasi sejenis yang telah berjalan, (3) perbandingan aplikasi sejenis yang telah ada, (4) identifikasi kebutuhan aplikasi, dan (5) pemodelan.

3) Perancangan

Perancangan aplikasi meliputi (1) perancangan antarmuka, (2) spesifikasi perangkat lunak dan (3) perangkat keras

4) Implementasi

Implementasi aplikasi meliputi (1) penulisan kode program, (2) uploading, (3) pengujian, dan (4) pendokumentasian.

\section{PUSTAKABASA}

PustakaBasa merupakan sebuah aplikasi kamus berbasis web yang dibangun untuk mendokumentasikan kosakata-kosakata dari seluruh bahasa daerah di Nusantara. PustakaBasa dapat diakses melalui perambah Internet di alamat http://www.pustakabasa.com.

Gambar 1 menunjukan tampilan antarmuka halaman awal aplikasi PustakaBasa yang diakses melalui perambah Mozilla Firefox v13.0.1.

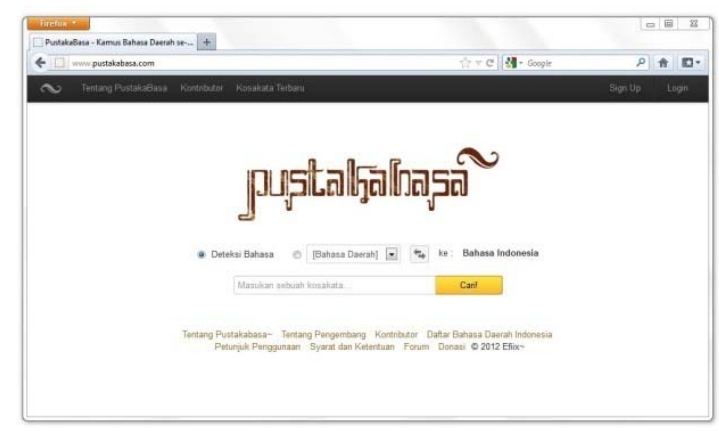

Gambar 1 Tampilan Antarmuka PustakaBasa

Fitur-fitur yang terdapat dalam aplikasi PustakaBasa adalah sebagai berikut:

a. Pencarian kosakata

Fitur pencarian kosakata terbagi menjadi 3 bagian, yaitu:

- Deteksi bahasa, untuk mencari arti dan asal bahasa daerah dari sebuah kosakata tertentu.

- Pencarian arti kosakata dari kosakata bahasa daerah tertentu. (bahasa daerah ke bahasa Indonesia)

- Pencarian kosakata bahasa daerah dari kosakata bahasa Indonesia. (bahasa Indonesia ke bahasa daerah)

b. Penambahan kosakata, untuk melakukan penambahan kosakata bahasa daerah yang belum ada di database PustakaBasa.

c. Sunting kosakata, untuk melakukan perbaikan kosakata dan atau makna dari kosakata bahasa daerah tertentu yang telah ada di database PustakaBasa.

d. Penambahan bahasa, untuk melakukan penambahan data bahasa daerah yang belum terdapat di PustakaBasa.

e. Sunting bahasa, untuk melakukan perbaikan data bahasa daerah dari bahasa daerah yang telah ada di PustakaBasa.

f. Melihat daftar kosakata terbaru, untuk melihat kosakata-kosakata terbaru yang telah ditambahkan oleh kontributor lain di PustakaBasa.

Sebagai sebuah aplikasi yang masih dalam tahap pengembangan, PustakaBasa memiliki beberapa batasan, yakni sebagai berikut:

a. Hanya berjalan di perangkat lunak perambah yang mendukung JavaScript.

b. Tampilannya tidak akan sempurna pada perambah yang belum mendukung CSS3. 


\section{PEMODELAN PUSTAKABASA}

Pemodelan yang digunakan dalam pengembangan aplikasi PustakaBasa adalah menggunakan UML versi 2.

\section{ACTIVITY DIAGRAM}

Activity diagram mendeskripsikan logika prosedural, proses bisnis dan aliran aktivitas dalam aplikasi yang sedang dirancang. Activity diagram akan menggambarkan bagaimana proses dimulai, decision yang mungkin terjadi, dan akhir dari aliran aktivitas [6]. Pada aplikasi PustakaBasa yang akan dibangun, maka activity diagram akan menggambarkan aliran proses mulai dari aplikasi dibuka melalui perambah Internet, proses pencarian kosakata, login user, serta aktivitas apa saja yang mungkin dilakukan oleh pengguna sampai pada aplikasi ditutup. Gambar 2 menunjukan activity diagram dari aplikasi PustakaBasa.

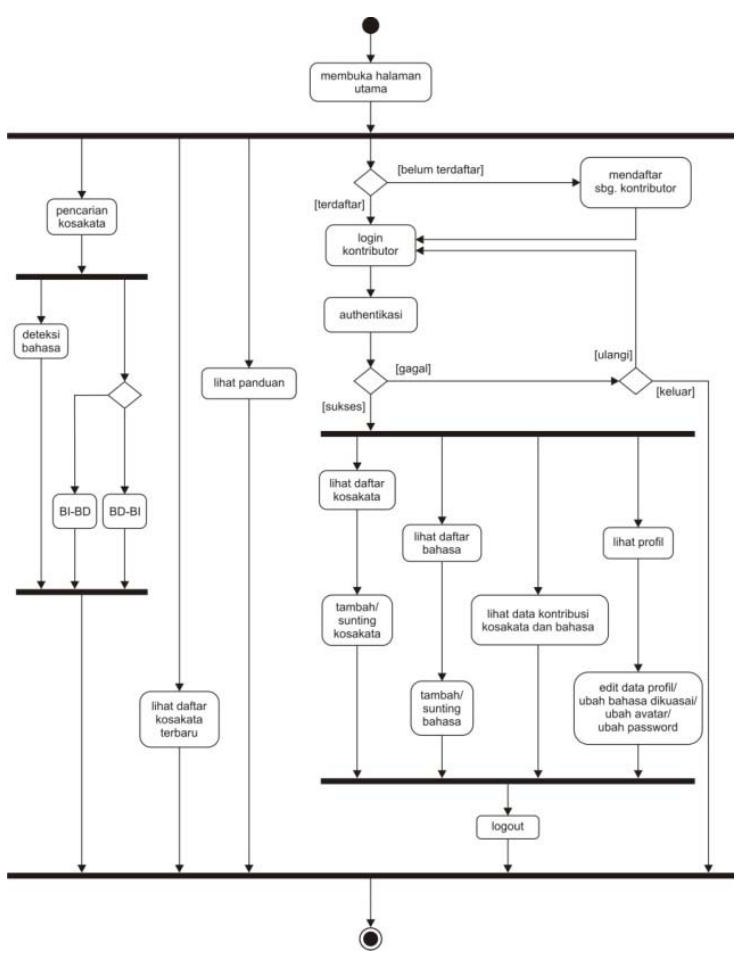

Gambar 2 Activity diagram PustakaBasa
Use case diagram berfungsi untuk menggambarkan fungsionalitas yang diharapkan dari sebuah sistem. Sebuah use case merepresentasikan sebuah interaksi antara aktor dengan sistem [7]. Adapun use case diagram dari PustakaBasa terlihat pada Gambar 3.

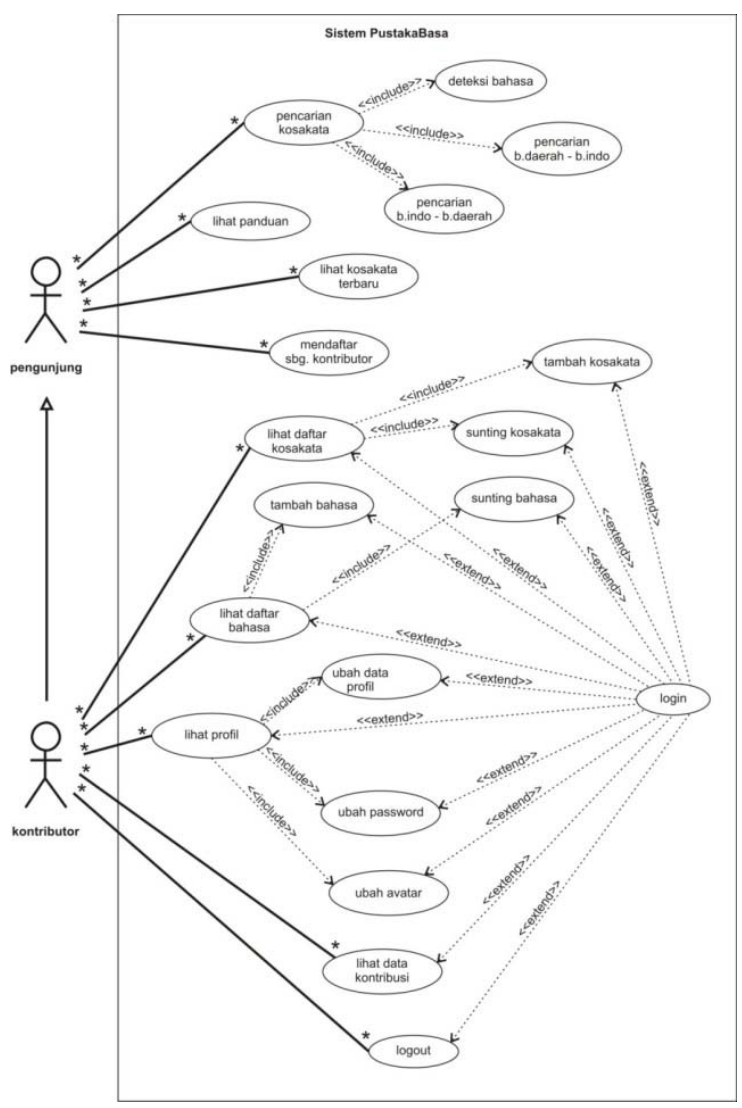

Gambar 3 Use case diagram

\section{CLASS DIAGRAM}

Berdasarkan analisis dari diagram-diagram sebelumnya, maka berikut ini merupakan identifikasi obyek dalam aplikasi yang diperlukan:

a. Obyek Kontributor

Kontributor adalah orang-orang yang berhak melakukan kontribusi baik itu penambahan kosakata, perbaikan kosakata, penambahan bahasa ataupun perbaikan bahasa. Aplikasi PustakaBasa sangat terkait dengan aktivitas kontributor, oleh karena itu diperlukan obyek khusus yang akan menangani kontributor. Adapun obyek tersebut adalah obyek Kontributor.

b. Obyek Artikel

\section{USE CASE DIAGRAM}


Obyek Artikel digunakan untuk menampilkan setiap konten yang ada dalam PustakaBasa. Konten di sini berupa artikel yang terdapat pada halaman panduan, halaman tentang PustakaBasa, halaman tentang pengembang dan halaman tentang cara melakukan donasi donasi.

c. Obyek Bahasa

Untuk mempermudah penanganan pengolahan bahasa maka akan dibuat sebuah obyek yang akan bertanggung jawab terhadap semua proses terkait bahasa. Obyek tersebut adalah obyek Bahasa.

d. Obyek arsipBahasa

Obyek ArsipBahasa digunakan untuk menyimpan semua perubahan yang dilakukan terhadap obyek Bahasa. Hal ini diperlukan untuk mengetahui perubahan apa saja yang telah terjadi pada obyek Bahasa.

e. Obyek bahasaDikuasai

Setiap kontributor bisa menguasai sebuah bahasa daerah atau lebih. Oleh karena itu penanganan terhadap bahasa yang dikuasai ini perlu dibuatkan sebuah obyek yang akan menangani setiap proses terkait bahasa yang dikuasai. Adapun obyek tersebut adalah bahasaDikasai.

f. Obyek Kosakata

Kosakata merupakan hal yang paling penting dalam pendokumentasian di PustakaBasa. Untuk menanganinya diperlukan sebuah obyek khusus, yaitu obyek Kosakata.

g. Obyek Arsip

Untuk kemudahan dalam kontrol setiap perubahan kosakata oleh kontributor, maka perlu dibuatkan obyek ArsipKosakata.

Dari hasil identifikasi obyek dan skenarioskenario yang ada, maka dapat dibuat sebuah class diagram [7]. Adapun class diagram PustakaBasa ditunjukan pada Gambar 4.

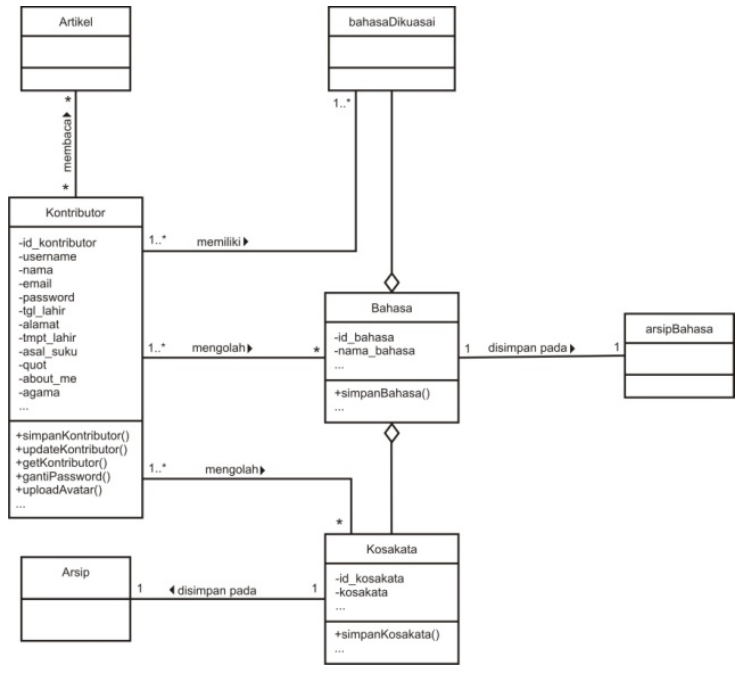

Gambar 4 Class Diagram PustakaBasa

\section{SEQUENCE DIAGRAM}

Sequence diagram digunakan untuk menggambarkan perilaku pada sebuah skenario. Diagram ini menunjukan sejumlah obyek dan message (pesan) yang dilakukan antara obyekobyek ini di dalam use case [7].

Sequence diagram untuk melakukan deteksi bahasa merupakan gabungan dari use case dalam proses pencarian kosakata dan use case deteksi bahasa. Adapun diagramnya ditunjukan pada Gambar 5.

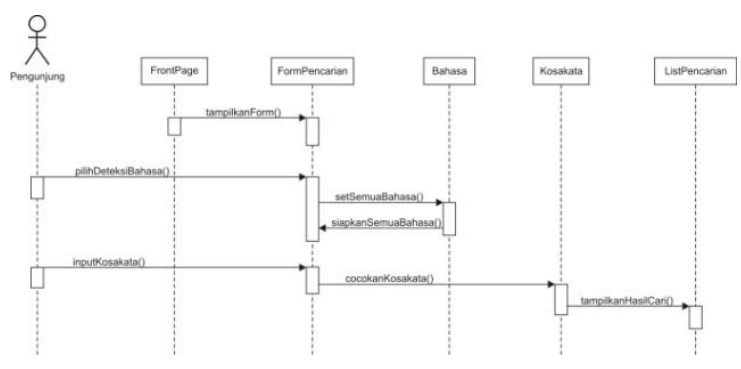

Gambar 5 Sequence diagram deteksi bahasa

Sequence diagram untuk melakukan pencarian arti kosakata dari bahasa daerah tertentu (bahasa daerah ke bahasa Indonesia) merupakan gabungan dari use case proses pencarian kosakata dan use case pencarian bahasa daerah ke bahasa Indonesia. Adapun diagramnya ditunjukkan pada Gambar 6. 


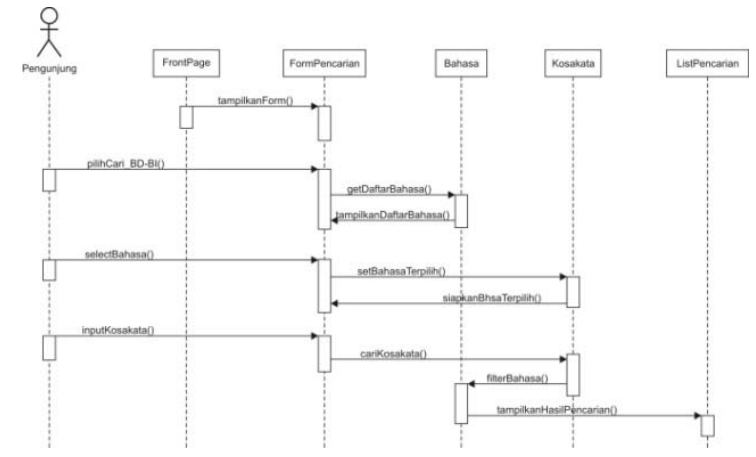

Gambar 6 Sequence diagram pencarian bahasa daerah ke bahasa Indonesia.

Sequence diagram untuk melakukan pencarian kosakata bahasa daerah dari kosakata bahasa Indonesia (bahasa Indonesia ke bahasa daerah). Pada diagram ini merupakan penggabungan antara use case pencarian kosakata dan use case pencarian kosakata bahasa daerah dari kosakata Indonesia itu sendiri. Adapun diagramnya ditampilkan pada Gambar 7.

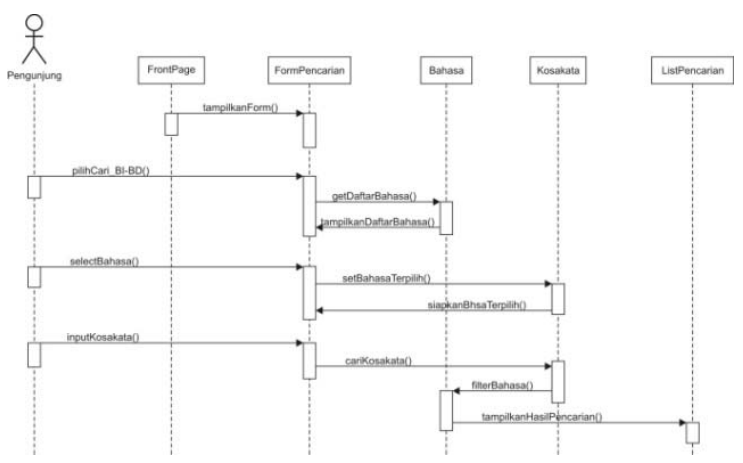

Gambar 7 Sequence diagram pencarian bahasa Indonesia ke bahasa daerah

Sequence diagram untuk melakukan penambahan kosakata baru merupakan gabungan dari use case lihat daftar kosakata dan use case tambah kosakata. Adapun diagramnya terlihat pada Gambar 8.

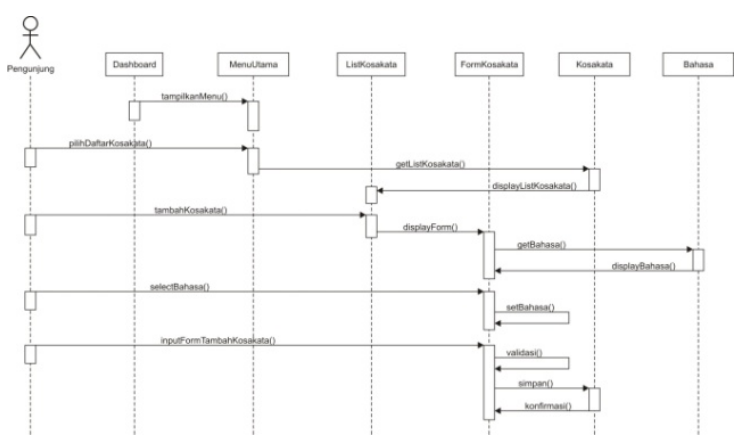

Gambar 8 Sequence diagram tambah kosakata
Sequence diagram untuk melakukan sunting kosakata merupakan gabungan dari use case lihat daftar kosakata dan use case sunting kosakata. Adapun diagramnya terlihat pada Gambar 9.

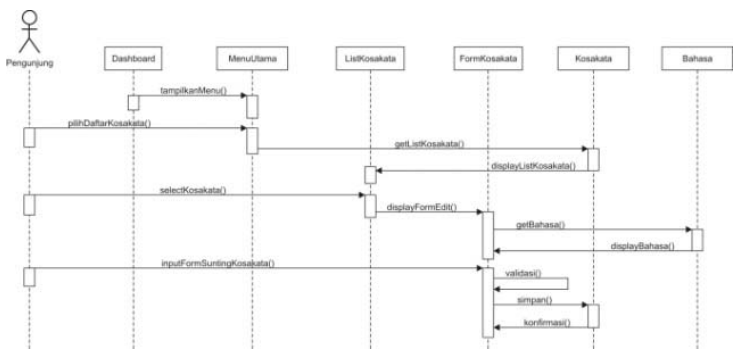

Gambar 9 Sequence diagram sunting kosakata

Sequence diagram untuk melakukan penambahan bahasa daerah merupakan gabungan dari use case lihat daftar bahasa dan tambah bahasa. Adapun diagramnya adalah seperti terlihat pada Gambar 10.

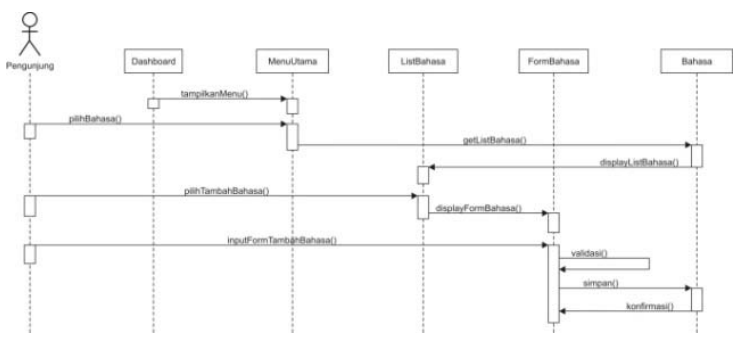

Gambar 10 Sequence diagram tambah bahasa

Sequence diagram untuk melakukan sunting bahasa daerah merupakan gabungan dari use case lihat daftar bahasa dan use case sunting bahasa. Diagramnya terlihat pada Gambar 11.

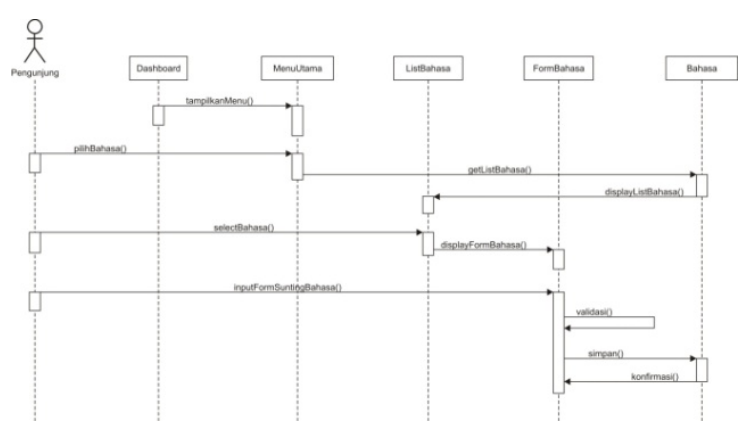

Gambar 11 Sequence diagram sunting bahasa

\section{PENERAPAN KONSEP CONTENT PADA PUSTAKABASA}

Open content adalah sebuah konsep tentang pengembangan konten secara terbuka. Open content dicetuskan pertama kali oleh David Wiley pada tahun 1998. Dalam open content, suatu konten bisa 
ditambahkan oleh siapa saja dan bisa disunting oleh siapa saja. Salah satu website yang menggunakan konsep ini adalah Wikipedia [8].

Pendekatan open content dapat mengurangi permasalahan distribusi atau penyebaran tulisan, gambar, atau materi lain yang digunakan untuk electronic learning (e-learning, electronic education, distance learning, dan kata kunci sejenisnya). Jika sebuah konten dideklarasi sebagai open content, maka kita tidak lagi dipusingkan terhadap masalah HaKI (Intellectual Property Rights, IPR) karena sudah jelas status hukumnya. Dalam hal pendidikan, kemudahan penyebaran ilmu merupakan salah satu kunci kesuksesan. Kemudahan mekanisme penyebaran merupakan sesuatu yang sangat didambakan [8].

Kelebihan dari open content adalah lebih cepatnya proses pelengkapan isi konten. Hal itu dikarenakan dikerjakan secara gotong-royong [8].

Indonesia memiliki 726 jenis bahasa daerah yang tersebar dari Sabang sampai Merauke. Jumlah tersebut tidaklah sedikit dan tentunya akan membutuhkan waktu yang sangat lama untuk mengumpulkan kosakatanya satu per satu apabila dilakukan oleh perorangan atau instansi tertentu.

Wikipedia adalah sebuah contoh nyata suksesnya penerapan konsep open content dalam mengumpulkan konten ensiklopedia. Dalam Wikipedia, setiap orang berhak untuk menambahkan artikel atau mengubah artikel yang telah ada sebelumnya. Bahkan setiap orang berhak untuk menyalin dan menyebarluaskan versi ubahan tersebut.

PustakaBasa akan dikembangkan dengan konsep open content, artinya setiap orang berhak untuk menambahkan kosakata baru dan memperbaiki kosakata yang telah ada bila memang diperlukan.

Kontributor bahasa PustakaBasa terbuka bagi seluruh masyarakat Indonesia, Artinya, siapa saja yang merasa bertanggung jawab dan peduli terhadap masalah bahasa berhak untuk menjadi kontributor bahasa di PustakaBasa dan berhak untuk melakukan kontribusi kebahasaan, seperti menambahkan kosakata baru atau memperbaiki kosakata yang telah ada, jika memang diperlukan.

Memang konsep open content bukanlah tanpa cacat. Dengan keterbukaan konten dan siapa saja bebas untuk menambahkan kosakata dan merubah kosakata yang telah ada akan memungkinkan adanya data yang tidak valid. Karena bisa saja ada orang yang berniat buruk untuk menambahkan kosakata yang salah atau merubah kosakata yang telah ada menjadi bermakna salah. Namun, hal tersebut bisa diatasi dengan kontrol secara bersamasama oleh komunitas.

Kontrol komunitas adalah sebuah kontrol kebenaran data oleh kontributor-kontributor lainnya yang mengerti akan bahasa tersebut. Karena setiap terjadi sebuah penambahan dan atau perubahan kosakata oleh seorang kontributor, maka akan muncul notifikasi tersebut kepada kontributor lainnya, khususnya yang mengerti bahasa tersebut. Dengan demikian, setiap penambahan atau perubahan kosakata akan dengan mudah dipantau oleh komunitas.

Selain seluruh masyarakat di Indonesia yang berhak menjadi kontributor, nantinya akan dibentuk sebuah tim yang terdiri dari para ahli bahasa yang akan selalu memantau aktivitas kontribusi yang terjadi, dengan demikian akan mengurangi kemungkinan munculnya data yang tidak valid. Juga untuk menekan terjadinya input data yang tidak diharapkan maka proses pengoreksian penambahan dan perubahan kosakata akan dilakukan sebelum kosakata tersebut dipublikasi.

\section{KESIMPULAN}

Aplikasi PustakaBasa dengan konsep open content yang dilengkapi dengan fitur pencarian kosakata, penambahan kosakata, sunting kosakata, penambahan bahasa dan sunting bahasa memungkinkan untuk pendokumentasian bahasa daerah lebih optimal, sehingga diharapkan dapat mengurangi kepunahan bahasa daerah di Indonesia khususnya dalam ragam tulis.

\section{PENGEMBANGAN LANJUTAN}

Pengembangan lanjutan dari aplikasi PustakaBasa adalah sebagai berikut:

a. Untuk menghargai kontributor yang telah bersedia membantu pengumpulan bahasa daerah, PustakaBasa harus dilengkapi dengan sistem penghargaan kontributor, seperti sistem like kosakata, rate kosakata dan pemberian sertifikat penghargaan online.

b. Agar kontributor semakin termotivasi untuk berkontribusi, maka PustakaBasa harus dilengkapi dengan sistem gelar berdasarkan banyaknya kontribusi yang diberikan.

c. Untuk kontrol bahasa yang lebih baik, maka PustakaBasa bisa dilengkapi dengan tingkatan level, yaitu kontributor biasa dan ahli bahasa. 
Ahli bahasa merupakan orang-orang tertentu yang memiliki pemahaman bahasa daerah yang lebih dari yang lainnya. Ahli bahasa memiliki hak lebih dalam kontrol bahasa.

d. Untuk menambah kemudahan dalam belajar bahasa daerah, maka PustakaBasa harus dilengkapi dengan fitur pengucapan kosakata (pronunciation) yang berasal dari penutur asli bahasa tersebut.

\section{PUSTAKA}

[1] Lewis, M.Paul (ed), (2009). "Ethnologue: Languages of the World". Sixteenth Edition. Dallas, Tex.: SIL International. Online version: http://www.ethnologue.com/. Diakses 26 Agustus 2012.

[2] Crystal, David. (2000). Language Death. United Kingdom: Cambridge University Press.

[3] Katubi. (2005). "Pemilihan Bahasa dan Perubahan Identitas Kultural". Dalam Katubi (ed.), Identitas Etnolinguistik Orang Hamap: Kode Etnisitas dan Bahasa Simbol. Jakarta: LIPI Press.

[4] SIL International, Indonesia Branch. (2001). Languages of Indonesia. Jakarta: SIL International, Indonesia Branch.

[5] Henry Tondo, Fanny. (2009). "Kepunahan Bahasa-bahasa Daerah: Faktor Penyebab dan Implikasi Etnolinguistis". Jurnal Ilmiah Masyarakat \& Budaya, Volume 11 No.2 Tahun 2009. Makalah Seminar Intern Pusat Penelitian Kemasyarakatan dan Kebudayaan (PMB)-LIPI pada tanggal 6 September 2007.

[6] Alan Dennis, Barbara Haley Wixom \& David Tegarden. (2005). Systems Analysis and Design with UML Version 2.0. Second Edition. Wiley. United States of America.

[7] Munawar. (2005). Pemodelan Visual dengan UML. Penerbit Graha Ilmu, Yogyakarta.

[8] Rahardjo, Budi. (2000). Mengadopsi Pola “Open content”. PPAU Mikroelektronika ITB. 